\title{
PAID-11: a brief measure of diabetes distress validated in adults with type 1 diabetes
}

Authors: Natalia Stanulewicz ${ }^{1}$ PhD, Peter Mansell ${ }^{2}$ DPhil, Debbie Cooke ${ }^{3}$ PhD, David Hopkins ${ }^{4}$ FRCP, Jane Speight ${ }^{5,6,7} \mathrm{PhD}$, \& Holly Blake ${ }^{8,9} \mathrm{PhD}$.

Affiliations: ${ }^{1}$ Division of Psychology, De Montfort University, UK; ${ }^{2}$ Department of Diabetes and Endocrinology, Nottingham University Hospitals NHS Trust, Nottingham, UK; ${ }^{3}$ School of Health Sciences, University of Surrey, UK; ${ }^{4}$ King's Health Partners' Institute of Diabetes, Endocrinology and Obesity, London, UK; ${ }^{5}$ School of Psychology, Deakin University, Geelong, Victoria, Australia; ${ }^{6}$ The Australian Centre for Behavioural Research in Diabetes, Diabetes Victoria, Melbourne, Australia; ${ }^{7}$ AHP Research, Hornchurch, UK; ${ }^{8}$ School of Health Sciences, University of Nottingham, UK; ${ }^{9}$ National Institute for Health Research (NIHR) Biomedical Research Centre, Nottingham, UK.

Natalia Stanulewicz (Corresponding Author)

Division of Psychology, School of Applied Social Sciences, De Montfort University Email: natalia.stanulewicz@dmu.ac.uk

Phone: +44 1163664399

Short Running title: PAID-11: brief measure of diabetes distress

Keywords: diabetes; emotional distress; screening tool; questionnaire; reliability; validity Word count: 4,257

Tables \& Figures: 3 tables, 1 figure (1a \& 1b) 


\begin{abstract}
Objective: The Problem Areas In Diabetes (PAID) questionnaire is widely used to assess emotional distress related to living with diabetes, although it is lengthy for routine clinical use. Our aim was to determine whether the original 20-item PAID questionnaire can be abbreviated, whilst maintaining its reliability, validity and utility.
\end{abstract}

Methods: We analysed data from the UK DAFNE (Dose Adjustment For Normal Eating) education programme for adults with Type 1 diabetes. Data were analysed at baseline $(n=1547)$ and 1 -year post intervention $(n=846)$. Exploratory factor analysis $(E F A)$ with principal axis factoring method was used to examine PAID responses within a random half of the baseline data $(n=746)$. Then, two confirmatory factor analyses (CFA) were conducted using the remaining baseline $(\mathrm{n}=801)$ and 1-year data. Reliability, predictive validity, convergent validity and responsiveness were also examined.

Results: Based on the EFA results, which were corroborated by CFA, an 11-item PAID questionnaire was identified with a cut-off score of 18 indicating severe diabetes distress. In the current sample, this brief version has high internal consistency (Cronbach's $\alpha=.93$ ). Predictive validity was demonstrated with the PAID-11 identifying severe diabetes distress from the original 20-item measure, with $95 \%$ sensitivity and $96 \%$ specificity. Convergent validity was demonstrated by strong positive correlations with HADS anxiety and depressive symptoms (average $r=.65$ and $r=.55$, respectively), while divergent validity was shown with weaker correlations with EQ5D health status (average $r=.37$ ). 
Conclusions: Based on present results, PAID-11 appears to be a valid and reliable measure, which seems suitable for use as a brief tool for the detection of diabetes distress in adults with type 1 diabetes. Importantly, this tool may reduce participant burden in multi-measure studies. However, further studies are urgently needed to determine the validity and utility of PAID-11 beyond the UK DAFNE population.

\section{'Research in context' summary}

\section{What is already known about this subject?}

- Elevated or severe diabetes distress is experienced by around one quarter of adults with diabetes living in the UK, at any one time.

- The Problem Areas In Diabetes (PAID) questionnaire is widely used to assess emotional distress related to living with diabetes, although it is lengthy for routine clinical use.

- Providing more time-efficient measures of diabetes distress can improve care for people with diabetes.

\section{What is the key question?}

- Can we identify a time-efficient, valid and reliable measure of diabetes distress?

\section{What are the new findings?}

- Brief version of the PAID questionnaire requiring just 11 responses is valid and reliable for assessing diabetes distress in adults with type 1 diabetes.

- The PAID-11 questionnaire has high predictive validity (95\% sensitivity and 96\% specificity) and a suggested cut-off point of $\geq 18$ is recommended for identifying those experiencing severe diabetes distress.

\section{How might this impact on clinical practice in the foreseeable future?}

- Clinicians may consider using PAID-11 to enable quick and easy identification of diabetes distress in routine practice, although further validation studies are needed to ascertain the validity and utility of PAID-11 beyond the UK DAFNE population. 


\section{PAID-11: a brief measure of diabetes distress validated in adults with type 1 diabetes}

\section{Introduction}

Type 1 diabetes is a complex condition involving a considerable burden of selfmanagement with the risk of both acute and chronic complications (1). The psychological impact can be profound. Emotional reactions, such as anger, guilt, shame, depression or anxiety are commonly experienced by individuals with diabetes (2). Emotional factors contribute to the high burden of the condition, and increased risk of premature mortality (3). Specifically, the emotional impact of living with diabetes has been termed diabetes distress (4). Elevated or severe diabetes distress is experienced by around one quarter of adults with diabetes living in the UK, at any one time (5). Similar, but also higher, rates of diabetes distress have been shown around the world $(6,7)$.

High levels of diabetes distress, such as feeling overwhelmed by the demands of living with diabetes can lead to sub-optimal self-management (e.g., 8). Both high HbA1c and severe hypoglycaemia are also associated with increased diabetes distress (e.g., 9). Further, diabetes distress (but not depression or depressive symptoms) is associated with higher HbA1c (e.g., 10), hence it is critical to have appropriate tools available to identify diabetes distress and enable early intervention.

Routine screening for distress in individuals with diabetes is increasingly recommended by professional bodies; for example, the most recent guidelines of the American Diabetes Association (11) and the UK National Institute for Clinical Excellence (1).

Six measures have been identified that capture the broad spectrum of diabetes distress (12). The most widely used is the 20-item Problem Areas in Diabetes scale (PAID), 
developed by Polonsky et al. (4). The psychometric characteristics of the PAID, together with its ability to detect change due to an intervention, have been supported in multiple studies, not only in clinical and research populations (e.g., 13,14,15,16), but also to assess the effectiveness of interventions, including the DAFNE (Dose Adjustment For Normal Eating) structured type 1 diabetes education programme $(17,18,19)$.

Despite the research pedigree of the PAID, its utility in a routine clinical setting may be limited due to its length and the time required to complete the questionnaire. It is possible that a version with fewer items but similar psychometric characteristics may prove equally reliable, particularly if applied to a selected population, such as those with type 1 diabetes only. Indeed, previous studies have noted that the 20-item PAID has high internal consistency reliability (Cronbach's $\alpha \geq .95$ ) (e.g., 20,21), suggesting there may be some item redundancy in the scale (22). Attempts have been made to develop 5-item and single-item versions of the PAID questionnaire (23). However, these scale reductions have been conducted using datasets from mixed populations of adults with type 1 diabetes and type 2 diabetes. There may be limitations with regards to the applicability of these findings to the type 1 diabetes population. Moreover, while the reduction in length might be suitable for initial screening, the PAID-5 and PAID-1 will potentially offer little clinical utility for understanding the sources of distress, as they are likely to have reduced content validity.

Our aim was to investigate: a) whether it is possible to construct a short-form of PAID with satisfactory psychometric properties using data from a large sample of adults with type 1 diabetes, and b) the reproducibility of the short-form, and its responsiveness to an educational intervention, using one-year follow-up data.

\section{Methods}

\section{DAFNE Research Database}


The data used in this study were taken from the DAFNE Research Database (DB031). DAFNE (Dose Adjustment For Normal Eating) is a 5-day group structured education programme, which trains adults with type 1 diabetes in the skills required for selfmanagement of flexible, intensive insulin therapy. DAFNE education provides adults with type 1 diabetes with the knowledge and self-management skills required for using optimal insulin dosing based on carbohydrate counting. DAFNE has been shown to improve glycaemic control, to reduce the frequency of episodes of severe hypoglycaemia and ketoacidosis, and to improve psychosocial outcomes, including diabetes-related distress (e.g., 18,24). Offering structured education to individuals with diabetes has been a recommended part of routine care in the UK since 2001 (25); to date, more than 43,000 adults with type 1 diabetes have undertaken DAFNE training (26) and many more have attended similar structured education courses, both in UK and other countries.

The DAFNE Research Database was developed as part of an NIHR-funded programme to evaluate and improve DAFNE structured education (27). The sample used in this study included adults with type 1 diabetes using multiple daily injections, recruited from 10 hospital sites in the UK, who participated in the DAFNE programme between 2008 and 2013. Participants were required to give written, informed consent for their data to be included in the database. The DAFNE Research Database incorporates anonymised baseline and post-course demographic, biomedical and psychosocial data, including PAID (15), Hospital Anxiety and Depression Scale (HADS: A and D; 28) and EuroQol 5D (EQ5D; 29).

\section{Participants}

From 2008 to 2013, 3184 adults with type 1 diabetes were recruited to the DAFNE Research Database. As we were determining and comparing PAID scores at baseline and at follow-up, we excluded those with no or incomplete PAID data and those experiencing major 
changes in circumstances that may, independently, have affected PAID scores, i.e. including pregnancy $(n=49)$ and those that converted to insulin pump therapy $(n=289)$ (at baseline or follow up). Of the remainder, complete PAID questionnaire data were available at baseline for $\mathrm{N}=1,547$ participants, at baseline but not at follow up for $\mathrm{N}=644$, and at both baseline and one-year post course follow-up for $\mathrm{N}=846$ participants.

\section{Statistical analysis}

All statistical analyses were conducted using IBM SPSS Statistics for Windows, Version 25.0 (Armonk, NY: IBM Corp) unless specified otherwise. We used descriptive statistics to examine participant characteristics.

We split the baseline dataset into two samples (A: $n=746$ and B: $n=801)$ determined at random. There were no significant differences between these two samples (see Table 1). Sample A was used for an initial Exploratory Factor Analysis (EFA). Baseline data were only marginally skewed, and so the method of principal axis factoring was implemented, as recommended in the literature (30). The sample size ( $n=746$; i.e., sample A) was deemed adequate for the analysis (sample $\mathrm{A}: \mathrm{KMO}=.95, p<.0001$ ).

Consistent with McGuire et al.'s approach (23), we removed items that loaded $<.50$ (item 15), and items that had high double-loadings on other factors (i.e. item 1, 2, and 18), especially as they did not meet the recommended thresholds for retaining (i.e., loading of .50.60 on first factor, and loadings $<.20-.30$ on second highest factor, and secondly the difference between cross-loadings was not >.30-.40) (31). Removing such items is suggested to clarify the solution (32). Lastly, we removed all remaining items with scores $\leq 1.0$ (i.e., rated on average as minor problems by the respondents) (excluded PAID items at this stage: 4, 5, 10, 14, and 17). 
The EFA was run twice (see Table 2), since if items are removed, it is recommended that the whole analysis is repeated (32). We then determined whether the structure obtained in sample A was reproducible by conducting confirmatory factor analyses (CFA) on data from sample B ( $n=801)$ and the one-year post-course dataset $(n=846)$. The criteria specified for a good model fit were based on the following statistics: Cmin/df $<5.0, \mathrm{CFI}>.95$, NFI $>.95$, and RMSEA <.08 (33). We used AMOS software (version 25; Chicago, USA) to perform CFA, with the maximum likelihood method. We assessed the internal consistency reliability of the PAID short-form using Cronbach's alpha in all three samples.

We used Pearson's correlation analysis to examine the convergent and divergent validity of the PAID short-form (baseline data) with the HADS and EQ5D, respectively. In accordance with established thresholds (34), it was expected that EQ5D, as a measure of general health status, would show low correlation with PAID $(r<.40)$, and that HADS, as a measure of emotional distress (albeit generic), would show higher correlations with PAID ( $r>.40$, optimally $r>.60)$. To examine known groups validity, we used an independent groups t-test to determine the differences in diabetes distress by gender, hypothesising that women would score higher than men, as in previous reports (23). To analyse change in the 20-item PAID score (i.e. from baseline to one-year follow-up), that is, to see whether there was an impact of time (pre/post intervention) on PAID score, a repeated measures ANOVA was conducted with time and PAID item number (i.e., to avoid multiple comparisons if not needed) as within-subject factors and PAID score as dependent variable. As the sphericity test for ANOVA was significant, indicating that the variances between pairs of scores were not equal, a Greenhouse-Geisser correction (a standard statistical procedure) was applied. Subsequently each PAID item was compared at pre and post-intervention with the use of paired t-test (with Bonferroni correction; see Table 3). Each PAID item was analysed separately, as this could provide useful information about item responsiveness and clinical 
utility, which the scale total alone cannot provide. The pre-post difference data were normally distributed, satisfying the requirements of the t-test. Finally, we examined the predictive validity of the PAID short-form by analysing its specificity and sensitivity (using ROC curve analysis and Youden index), against the original 20-item scale. We ascribed the same weights to both sensitivity and specificity, and used Youden index $(\mathrm{J})$ to determine the best cut-off point, as recommended by Kumar and Indrayan (35).

\section{Results}

\section{Participants' characteristics}

The characteristics of those participants with PAID data at both baseline and followup are detailed in Table 1. The 644 participants ( $43 \%$ female; $p<.02$ ) who had complete PAID baseline data but did not complete one-year follow-up were, at baseline, significantly younger (42.36 (13.50) years, $p<0.001)$, had higher HbAlc (9.11\% (1.78), 76.01mmol/mol (19.41), $p<0.001$ ), and significantly higher scores on PAID-20 (31.18 (20.99), $p<0.001)$, HADS anxiety symptoms (6.77 (4.46), $p=0.25)$ and shorter time since diagnosis (21.88 (12.37) years, $p=.03$ ) than those with baseline and follow up data ( $\mathrm{n}=903$ at baseline, but then reduced to 846 due to pregnancies and using pumps at follow-up). There were no significant differences between these groups in their levels of HADS depression symptoms (4.08 (3.72), $p=.27$ ), BMI (26.38 (5.26), $p=.70)$ and EQ5D health status (6.14 (1.53), $p=.32)$.

When comparing the characteristics of sample A $(n=746)$ and $B(n=801)$, that we derived at by randomly splitting baseline data, with approximately $50 \%$ per sample, there were no significant differences found (see Table 1), supporting the appropriateness of the random split.

[insert Table 1 here] 


\section{Exploratory factor analysis (EFA), scale reduction and internal consistency reliability -}

\section{baseline Sample A}

Based on Eigenvalues $>1$, the initial solution determined three factors, explaining $62.42 \%$ of the variance. The scree plot and factor loadings suggested that a one-factor solution $($ Eigenvalue for first factor $=10.17)$, with few items cross-loading, provided a better fit. The single factor solution explained $50.84 \%$ of the variance. All items apart from one (i.e. item 15) loaded $>.50$ (see Table 2), suggesting satisfactory construct validity. Thus, we excluded this item. After applying other criteria specified in methods section, we derived at 11 final items (see Appendix A).

A second EFA was conducted using only the selected 11 items (KMO=.94). This demonstrated a one-factor solution (Eigenvalue for first factor $=6.65$ ), explaining $60.49 \%$ of the variance. The internal consistency of the PAID-11 in sample A was excellent $(\alpha=.93)$.

[insert Table 2 here]

\section{Confirmatory factor analysis (CFA) and internal consistency reliability - baseline}

\section{Sample B and one-year follow-up}

Using data from baseline sample B ( $\mathrm{n}=801)$, a CFA showed all 11 items were assigned to a single factor, and following modification indices (values $>20$ ), covariates between the error terms were established (see Fig. 1a). The specified model presented the following model fit indices: $\mathrm{X}^{2}(36)=132.13, \mathrm{p}<.0001, \mathrm{Cmin} / \mathrm{df}=3.67, \mathrm{CFI}=.982, \mathrm{NFI}=.975, \mathrm{RMSEA}=$ .058. The large sample size affected the $\mathrm{X}^{2}$, but model fit indices indicated a good fit of the data to the model.

Using data from the one-year follow-up $(n=846)$, the second confirmatory factor analysis showed all 11 items were assigned to single factor, and following modification 
indices (values >20), covariates between the error terms were established (see Fig. 1b). The final model with PAID-11 (Fig. 3) showed a good fit to the data, with the model fit indices being: $\mathrm{X}^{2}(39)=183.31, \mathrm{p}<.0001, \mathrm{Cmin} / \mathrm{df}=4.70, \mathrm{CFI}=.976, \mathrm{NFI}=.970, \mathrm{RMSEA}=.066$. Again, the large sample size affected the $\mathrm{X}^{2}$, but model fit indices signified a good fit of the data to the model. The internal consistency of the PAID-11 was excellent (sample B: $\alpha=.925$; follow-up: $\alpha=.931)$.

[insert Fig. 1a and Fig. 1b here]

The mean total score for PAID-11 was $\mathrm{M}=15.01(\mathrm{SD}=10.18)$ in sample $\mathrm{A}, \mathrm{M}=15.01$ $(\mathrm{SD}=9.84)$ in sample $\mathrm{B}$, and $\mathrm{M}=11.26(\mathrm{SD}=9.08)$ at follow-up.

\section{Construct validity of PAID-11 - all samples}

The convergent validity of the PAID-11 in sample A was demonstrated by its strong positive correlations with the HADS anxiety symptoms (sample A: $r=.66$; sample B: $r=.63$; follow up: $r=.67$; all $p<.001$ ) and HADS depression symptoms (sample A: $r=.54$; sample B: $r=.56$; follow-up: $r=.56$; all $p<.001$ ), indicating that anxiety and depression symptoms increase alongside increases in diabetes distress, and are closely related generic and diabetesspecific versions of an emotional well-being construct.

The divergent validity of PAID-11 was demonstrated, as expected, by its weaker correlation with EQ5D scores (sample A: $r=.32$; sample B: $r=.40$; follow-up: $r=.39$; all $p<.001)$, demonstrating that self-reported general health worsens as diabetes distress increases but that the two are distinct constructs.

With respect to known groups validity, we observed that women in sample A $(\mathrm{M}=16.40, \mathrm{SD}=10.18, \mathrm{n}=352)$ scored on average significantly higher $(t(743)=-2.68, p<.0001$; 
Mean difference $=-2.68,95 \% \mathrm{CI}=-4.13,-1.22)$ than men $(\mathrm{M}=13.73, \mathrm{SD}=10.01, \mathrm{n}=393)$ on the new PAID-11, with an effect size of Cohen's $d=-0.27$ (95\% CI=-.41;-.12). Essentially similar results were observed in sample B and in the follow-up sample. The mean score on PAID-11 for females (sample B: $\mathrm{M}=17.06, \mathrm{SD}=10.11, \mathrm{n}=367$; follow up: $\mathrm{M}=12.22, \mathrm{SD}=8.90$, $\mathrm{n}=406$ ) and males (sample $\mathrm{B}: \mathrm{M}=13.30, \mathrm{SD}=9.29, \mathrm{n}=433$; follow up: $\mathrm{M}=10.38, \mathrm{SD}=9.18$, $\mathrm{n}=439$ ) differed significantly: at baseline (Mean difference $=-3.76,95 \% \mathrm{CI}=-5.11,-2.41$ ) $(t(798)=-5.48, p<.0001)$ and at follow up (Mean difference $=-1.84,95 \% \mathrm{CI}=-3.06,-.61$; $t(843)=-2.95, p=.003)$. The effect size for this difference was equal to Cohen's $d=-.39(95 \%$ $\mathrm{CI}=-.53 ;-.25)$ in sample $\mathrm{B}$, and Cohen's $d=-.20(95 \% \mathrm{CI}=-.33 ;-.07)$ at follow up.

\section{Criterion and predictive validity of PAID-11 - baseline Samples A and B}

Criterion validity was demonstrated with the 11-item scale correlating highly with the original 20-item scale (sample A: $r=.974, p<.001, \mathrm{n}=746$; sample $\mathrm{B}$ : $\mathrm{r}=.973, \mathrm{n}=801$; follow up: $r=.978, p<.001, \mathrm{n}=846)$. Lastly, we evaluated the ability of the PAID-11 to predict severe diabetes distress on the PAID-20 using two cut-off scores, as used in previous studies.

Using a PAID-20 cut-off score of 33, consistent with the approach used by McGuire at el. (23), the area under the curve analysis for PAID-11 showed that $\mathrm{C}=.990$ ( $\mathrm{SE}=.002 ; 95 \%$ $\mathrm{CI}=.987, .994)$ demonstrating high diagnostic accuracy of PAID-11. Using the Youden Index $(\mathrm{J})$, the best cut-off score for PAID-11 was determined to be a score of $17.5(\mathrm{~J}=.905$ for this point, in comparison $\mathrm{J}$ for score of $18.50=.879$, and $\mathrm{J}$ for score of $16.50=.895$ ). This cutoff had $95 \%$ sensitivity and $96 \%$ specificity in the PAID-11. This cut-off classified $36.4 \%$ $(n=563)$ of the full baseline sample as experiencing severe diabetes distress, and $22.7 \%$ $(n=192)$ as experiencing severe diabetes distress at one-year post-intervention.

Using a PAID-20 cut-off score of 40 (36), the area under the curve analysis for PAID11 showed, very similarly, that $\mathrm{C}=.990(\mathrm{SE}=.002 ; 95 \% \mathrm{CI}=.987, .993)$ demonstrating high 
diagnostic accuracy of PAID-11. Following the Youden Index method, the best cut-off score for PAID-11 was determined to be a score of 19.5 ( $\mathrm{J}=.903$ for this point, in comparison $\mathrm{J}$ for score of $18.50=.885$, and $\mathrm{J}$ for score of $20.50=.880$ ). This cut-off was linked to $96 \%$ sensitivity and 94\% specificity of PAID-11. This cut-off classified 31.2\% ( $n=483)$ of the full baseline sample as experiencing severe diabetes distress, and $18.6 \%(\mathrm{n}=157)$ as experiencing severe diabetes distress at one-year post-intervention.

However, as the cut-off of 17.5 shows high sensitivity and marginally higher specificity, we recommend that a PAID-11 score of 18 or more (out of a maximum of 44) is used to identify severe diabetes distress.

\section{Responsiveness and Stability}

Lastly, we examined whether the PAID-11 is able to detect change in diabetes distress following a structured type 1 diabetes education intervention $(n=846)$. Change scores were normally distributed. For the PAID-20, there was a main effect of time $(F(1,845)=146.09$, $\left.p<.001 ; \eta^{2}=.15\right)$ and item number $\left(F(13.39,11313.50)=270.48, p<.001, \eta^{2}=.24\right)$, together with a significant interaction $\left(F(15.93,13458.99)=12.61, p<.001, \eta^{2}=.02\right)$.

Adjusting for multiple comparisons, all item scores (apart from item 18) showed a statistically significant reduction from baseline to one-year follow-up.

For the PAID-11, there was a significant decrease in diabetes distress between baseline $(\mathrm{M}=14.16, \mathrm{SD}=9.71)$ and one-year post-intervention $(\mathrm{M}=11.26, \mathrm{SD}=9.08)$ with a mean difference of 2.90 points $(\mathrm{SD}=8.10 ; 95 \% \mathrm{CI}=2.36,3.45 ; t(845)=10.42, p<.001)$. This change corresponds to small effect size (Cohen's $d=-.36 ; 95 \% \mathrm{CI}=-.44 ;-.25)$ with a $20.48 \%$ reduction in PAID-11 score, and thus demonstrated that PAID-11 is sensitive for observing change in diabetes distress.

[insert Table 3 here] 


\section{Discussion}

This study indicates that a brief version of the PAID questionnaire requiring just 11 responses is valid and reliable for assessing diabetes distress in adults with type 1 diabetes. The PAID-11 questionnaire has high predictive validity (95\% sensitivity and 96\% specificity) and a suggested cut-off point of $\geq 18$ is recommended for identifying those experiencing severe diabetes distress.

Using data from a large UK sample of adults with type 1 diabetes, we demonstrated that the original 20-item PAID (4) was best described as a scale with a one-factor solution with few double-loading items. While several previous studies have found the PAID-20 to be uni-dimensional, i.e. assessing one underlying latent construct of diabetes distress (e.g., 15,16), several have identified multi-dimensional structures, i.e. two- (e.g., 37) three- (e.g., 21) or even four-factors (14). The PAID-11 seems to present a much clearer one-factor solution, and therefore supports the use of a single total score better than the full PAID-20 scale. The PAID-11 offers a high level of internal consistency reliability (but with less evidence of redundancy), with the considerable advantage of comprising almost half the items (and therefore half the time required for completion) as the original PAID-20 scale. Further, the psychometric properties of PAID-11 have been tested in a larger sample compared with prior short versions of PAID (5-item and single item). In comparison to McGuire et al. (23) who obtained only 10 items loading >.50 when conducting EFA, all our items apart from one (item 15) loaded >.50. Interestingly, the same item has been found to possess the highest item misfit in another study in which Rasch analysis was applied to the PAID-20 (16). Importantly, PAID-11 offers better screening utility (95\% sensitivity and $96 \%$ specificity) than that offered by PAID-5 (i.e., $94 \%$ and $89 \%$ respectively; 23 ).

The availability of a large, longitudinal data dataset has enabled us to demonstrate that PAID-11 is sensitive to capturing change in diabetes distress following an intervention. The 
comparison of the effect size for change in diabetes distress observed with PAID-11 (Cohen's $d=-.36)$ was in line with previous literature, suggesting intervention effectiveness for diabetes distress ranging from small (Cohen's $d=.31)$ to moderate (Cohen's $d=.65)(38)$. The obtained reduction in diabetes distress $(20.48 \%)$ was highly comparable with other work demonstrating a $22.5 \%$ reduction (39) using a smaller sample.

The consistent correlations with other measures of emotional distress, such as HADS anxiety and depressive symptoms, and with the EQ5D measure of generic health status, lend support to the convergent and divergent validity of PAID-11. Adjusted analyses for multiple statistical tests suggest the findings are unlikely to have arisen spuriously. Although PAID-11 correlated positively with EQ5D scores as a measure of health status (average $r=.37$ ), this correlation was slightly lower than that reported by McGuire et al. (23) who used the WHO-5 $(r=.47)$, potentially suggesting a more specific measure that was arrived at. However, it has been demonstrated that the EQ5D suffers from ceiling effects with type 1 diabetes samples. For example, Peasgood and colleagues (40) identified that approximately $50 \%$ of respondents in each time period reported a health state that was valued at 1.

Some indirect support for the items chosen to create PAID-11 stems from a previous study (36) that examined each item's score for those with clinical depression. When comparing the items that create PAID-11 with the results reported by Hermanns et al. (36), it can be observed that nine of our PAID-11 items score highest in that sample. Whereas the remaining two items of PAID-11 (item 8 and 11) in the above study still score higher than the majority of the excluded items. Similar observations can be made when comparing chosen PAID-11 items with the highest scoring items in another sample that underwent a structured education (19). Here, nine of the chosen PAID-11 items were among 11 highest scored items, while all 11 items from the PAID-11 were included within the 13 top-scored items. These 
similar results from different samples seem to support the importance of the selected items for assessing diabetes distress.

We propose that PAID-11 has greater content validity and clinical utility than shorter versions of this scale (e.g., PAID-5, PAID-1) due to the breadth of issues retained in the measure. Harsh reduction of a full scale and failure to include a sufficient number of aspects that are known to contribute to the construct being measured may serve to reduce validity of the scale and its utility (41). Although the main concerns related to diabetes might be similar for many patients and their families, there is likely to be some level of variation that would be challenging to identify through single item or 5-item measures.

The abbreviated PAID-11 questionnaire is likely to be useful for clinicians seeking to incorporate a measure of psychological distress related to diabetes into their routine clinical consultations, given that almost halving the items from the full scale should equate to a considerable reduction in the time required for completion, with retention of excellent psychometric characteristics. This scale might also represent a good choice for research projects in which multiple measures are used, necessitating brevity as one of the criteria for selecting scales. It should be noted, however, that this is the first study introducing the PAID11, and thus further validation efforts are required to replicate these findings in other populations and fully ascertain its psychometric validity and utility.

\section{Study Limitations}

Our sample included only UK adults with type 1 diabetes using basal-bolus insulin therapy attending a structured type 1 diabetes education course. The fact that our sample had participated in structured education might be seen as a limitation. However, it is important to note that: a) the DAFNE inclusion criteria are broad and do not exclude many people with type 1 diabetes; b) structured education has been a standard care recommendation for adults 
with diabetes in the UK since 2001 (25). Thus, it could be argued that the vast majority of individuals with diabetes in the UK should receive similar education and our sample is likely to be fairly representative of the broader population with type 1 diabetes. Nevertheless, not everyone attends structured education programmes, and it is known that those who do not attend are often less affluent, have logistical or other medical issues, or do not perceive the value of such education (42). Thus, the psychometric properties of the PAID-11 need to be confirmed in other care settings, populations (including type 2 diabetes) and countries (especially ones where structured education is not a part of routine care). Using other methodological approaches (e.g., Rasch analysis), as well as conducting prospective studies, would be valuable, although it would be a major undertaking to study a population as large as the one in the current study.

The sample size was also influenced by a relatively substantial drop-out between baseline and year 1 assessment, although this is a common occurrence in longitudinal studies. Nevertheless, as the analyses focused on intragroup rather than intergroup comparisons that issue should have a limited effect on the results presented (43); as such, we do not expect that such a drop-out has affected our results significantly. Nevertheless, in our study, those who dropped out did have elevated diabetes distress and also higher anxiety level, which may have contributed to their attrition. Indeed, there is evidence to suggest that anxiety in particular may affect expectations about treatments and be associated with drop-out (44). It would be valuable, therefore, for future studies to investigate whether diabetes distress is related to intervention attrition through comparison of diabetes distress levels in those who continue applying the principles of DAFNE post-course with those who do not.

Notwithstanding these study limitations, psychometric testing of PAID-11 has been conducted in a large sample, and demonstrates that PAID-11 is responsive to intervention. 


\section{Conclusion}

This study has introduced and validated the PAID-11, a brief measure of emotional distress related to living with and managing diabetes. The PAID-11 offers similar utility to the original 20-item measure (4) with the advantage of almost half the time required for administration and lower associated burden. It has greater sensitivity and specificity than the 5-item version (23). We recommend that researchers consider the PAID-11 as an alternative to the PAID-20, to reduce participant burden in multi-measure studies. Clinicians may consider using the tool to enable quick and easy identification of diabetes distress in routine practice, although further validation studies are required to assure the utility of PAID-11 in other populations beyond the DAFNE population in which the PAID-11 was tested and analyzed in this study.

\section{Acknowledgements}

The authors wish to thank the National Institute for Health Research (NIHR) Dose Adjustment for Normal Eating (DAFNE) Study Group for access to the data (DAFNE Research Database: DB031/16HB), the participants who took part in the original study and Dr Andrea Venn for assistance with the data analysis plan. This study was partially supported by grant funding held by PM at Nottingham University Hospitals NHS Trust (13EN003). JS is supported by core funding to the Australian Centre for Behavioural Research in Diabetes derived from the partnership for better health between Diabetes Victoria and Deakin University.

\section{Author contributions}

NS, HB, PM, DC and DH developed the study concept. Data preparation, analysis and interpretation were performed by NS under supervision of HB. NS drafted the manuscript and is guarantor for the article contents. All authors provided critical revisions and approved the final version of the manuscript.

\section{Declaration of interests}


The authors confirm that there is no conflict of interest.

This study was presented at the 53rd Annual Meeting of the European Association for the Study of Diabetes as a poster presentation. Details below.

PM, NS, DH, DC, HB. Validation of a shortened 11-item version of the Problem Areas in Diabetes scale to measure distress in adults with type 1 diabetes. 53 rd Annual Meeting of the European Association for the Study of Diabetes. 11-15th September 2017, Lisbon, Portugal.

\section{References:}

1. National Institute for Health and Care Excellence. Type 1 diabetes in adults: Diagnosis and management. NICE guideline (NG17), 2016. Available from https://www.nice.org.uk/guidance/ng17. Accessed 5 August 2018

2. Stuckey HS, Mullan-Jensen CB, Reach G, et al. Personal accounts of the negative and adaptive psychosocial experiences of people with diabetes in the second diabetes attitudes, wishes and needs (DAWN2) study. Diabetes Care 2014;37:2466-2474

3. Huxley RR, Peters SAE, Mishra GD, Woodward M. Risk of all-cause mortality and vascular events in women versus men with type 1 diabetes: A systematic review and meta-analysis. The Lancet Diabetes Endocrinol 2015;3:198-206

4. Polonsky WH, Anderson BJ, Lohrer PA, et al. Assessment of diabetes-related distress. Diabetes Care 1995;18:754-760

5. Dennick K, Sturt J, Hessler D, et al. High rates of elevated diabetes distress in research populations: A systematic review and meta-analysis. Int Diabetes Nurs 2016;12:93-107

6. Perrin NE, Davies MJ, Robertson N, Snoek FJ, Khunti K. The prevalence of diabetesspecific emotional distress in people with type 2 diabetes: A systematic review and meta-analysis. Diabet Med 2017;34:1508-1520

7. Speight J, Browne JL, Holmes-Truscott E, Hendrieckx C, Pouwer F. Diabetes MILESAustralia 2011 survey report [article online], 2011. Vic, Melbourne. Diabetes Australia. Available from https://static.diabetesaustralia.com.au/s/fileassets/diabetesaustralia/4e052ae5-2d13-421e-b6f8-5e323b5c48a6.pdf. Accessed 4 July 2018

8. Ogbera A, Adeyemi-Doro A. Emotional distress is associated with poor self care in type 2 diabetes mellitus. J Diabetes 2011;3:348-352

9. Hendrieckx C, Halliday JA, Bowden JP, et al. Severe hypoglycaemia and its association with psychological well-being in Australian adults with type 1 diabetes attending specialist tertiary clinics. Diabetes Res Clin Pract 2014;103:430-436

10. Fisher L, Mullan JT, Arean P, Glasgow RE, Hessler D, Masharani U. Diabetes distress but not clinical depression or depressive symptoms is associated with glycemic control in both cross-sectional and longitudinal analyses. Diabetes Care 2010;33:23-28 
11. American Diabetes Association. Standards of Medical Care in Diabetes-2017. Diabetes Care 2017;40(Suppl. 1):S1-S135

12. Dennick K, Sturt J, Speight J. What is diabetes distress and how can we measure it? A narrative review and conceptual model. J Diabetes Complications 2017;31:898-911

13. Eigenmann CA, Colagiuri R, Skinner TC, Trevena L. Are current psychometric tools suitable for measuring outcomes of diabetes education? Diabet Med 2009;26:425-436

14. Snoek FJ, Pouwer F, Welch GW, Polonsky WH. Diabetes-related emotional distress in Dutch and U.S. diabetic patients: Cross-cultural validity of the Problem Areas In Diabetes scale. Diabetes Care 2000;23:1305-1309

15. Welch G, Jacobson AM, Polonsky WH. The Problem Areas in Diabetes Scale: An evaluation of its clinical utility. Diabetes Care 1997;20:760-766

16. Fenwick EK, Rees G, Holmes-Truscott E, Browne JL, Pouwer F, Speight J. What is the best measure for assessing diabetes distress? A comparison of the Problem Areas in Diabetes and Diabetes Distress Scale: Results from Diabetes MILES-Australia. $J$ Health Psychol 2018;23:667-680

17. Gunn D, Mansell P. Glycaemic control and weight 7 years after Dose Adjustment For Normal Eating (DAFNE) structured education in type 1 diabetes. Diabet Med 2012;29:807-812

18. Hopkins D, Lawrence I, Mansell P, et al. Improved biomedical and psychological outcomes 1 year after structured education in flexible insulin therapy for people with type 1 diabetes. The U.K. DAFNE experience. Diabetes Care 2012;35:1638-1642

19. Speight J, Holmes-Truscott E, Harvey DM, et al. Structured type 1 diabetes education delivered in routine care in Australia reduces diabetes-related emergencies and severe diabetes-related distress: The OzDAFNE program. Diabetes Res Clin Pract 2016;112:65-72

20. Bjarkoy Strandberg R, Graue M, Wentzel-Larsen T, Peyrot M, Rokne B. Relationships of diabetes-specific emotional distress, depression, anxiety, and overall well-being with $\mathrm{HbA}_{1 \mathrm{c}}$ in adult persons with type 1 diabetes. J Psychosom Res 2014;77:174-179

21. Papathanasiou A, Koutsovasilis A, Shea S, et al. The Problem Areas in Diabetes (PAID) scale: Psychometric evaluation survey in a Greek sample with type 2 diabetes. $J$ Psychiatr Ment Health Nurs 2014;21:345-353

22. Tavakol M, Dennick R. Making sense of Cronbach's alpha. Int J Med Educ 2011;2:53-55

23. McGuire BE, Morrison TG, Hermanns N, et al. Short-form measures of diabetes-related emotional distress: The Problem Areas in Diabetes scale (PAID)-5 and PAID-1. Diabetologia 2010;53:66-69

24. Speight J, Amiel SA, Bradley C, et al. Long-term biomedical and psychosocial outcomes following DAFNE (Dose Adjustment For Normal Eating) structured education to 
promote intensive insulin therapy in adults with sub-optimally controlled type 1 diabetes. Diabetes Res Clin Pract 2010;89:22-29

25. Department of Health. Modern standards and service models. National service framework for diabetes: Standards. 2001. Available from https://assets.publishing.service.gov.uk/government/uploads/system/uploads/at tachment_data/file/198836/National_Service_Framework_for_Diabetes.pdf. Accessed 5 October 2018

26. DAFNE website. Vital Statistics. Available from http://www.dafne.uk.com/. Accessed 5 October 2018.

27. Heller S, Lawton J, Amiel S, et al. Improving management of type 1 diabetes in the UK: The Dose Adjustment For Normal Eating (DAFNE) programme as a research test-bed. A mixed method analysis of the barriers and facilitators to successful diabetes self management, a health economic analysis, a cluster RCT of different models of delivery of an educational intervention and the potential of insulin pumps and additional educator input to improve outcomes. Southampton (UK): NIHR Journals Library; 2014 Dec. (Programme Grants for Applied Research, No. 2.5.) Available from https://www.ncbi.nlm.nih.gov/books/NBK263953/ doi: 10.3310/pgfar02050

28. Zigmond AS, Snaith RP. The Hospital Anxiety and Depression Scale. Acta Psychiatr Scand 1983:67:361-370

29. EuroQol Group. EuroQol-a new facility for the measurement of health-related quality of life. Health Policy 1990;16:199-208

30. Fabrigar LR, Wegener DT, MacCallum RC, Strahan EJ. Evaluating the use of exploratory factor analysis in psychological research. Psychol Methods 1999;4:272-299

31. Matsunaga M. How to factor-analyse your data right: do's, don'ts, and how-to's. Int J Psychol Res 2010;3:97-110

32. Watson R, Thompson DR. Use of factor analysis in Journal of Advanced Nursing: Literature review. $J$ Adv Nurs 2006;55:330-341

33. Kline RB. Principles and Practice of Structural Equation Modelling ( $3^{\text {rd }}$ Edition). New York, NY, Guilford, 2011

34. Godwin M, Pike A, Bethune C, Kirby A, Pike A. Concurrent and convergent validity of the Simple Lifestyle Indicator Questionnaire. ISRN Family Med 2013:529645

35. Kumar R, Indrayan A. Receiver Operating Characteristic (ROC) curve for medical researchers. Indian Pediatr 2011;48:277-287

36. Hermanns N, Kulzer B, Krichbaum M, Kubiak T, Haak T. How to screen for depression and emotional problems in patients with diabetes: Comparison of screening characteristics of depression questionnaires, measurement of diabetes-specific emotional problems and clinical assessment. Diabetologia 2006;49:469-477 
37. Miller ST, Elasy TA. Psychosomatic evaluation of the Problem Areas in Diabetes (PAID) survey in Southern, rural African American women with type 2 diabetes. BMC Public Health 2008;8:70

38. Welch G, Weinger K, Anderson B, Polonsky WH. Responsiveness of the Problem Areas in Diabetes (PAID) questionnaire. Diabet Med 2003;20:69-72

39. Weinger K, Jacobson AM. Psychosocial and quality of life correlates of glycemic control during intensive treatment of type 1 diabetes. Patient Educ Couns 2001;42:123-131

40. Peasgood T, Brennan A, Mansell P, Elliott J, Basarir H, Kruger J. The impact of diabetesrelated complications on preference-based measures of health-related quality of life in adults with type I diabetes. Med Decis Making 2016;36:1020-1033

41. Clark LE, Watson D. Constructing validity: Basic issues in objective scale development. Psychol Assess 1995;7:309-319

42. Horigan G, Davies M, Findlay-White F, Chaney D, Coates V. Reasons why patients referred to diabetes education programmes choose not to attend: A systematic review. Diabet Med 2016;34:14-26

43. Deeg DJH. Attrition in population studies: Does it affect the generalizability of the findings? An introduction to the series. J Clin Epidemiol 2002;55:213-215

44. Santana L, Fontenelle LF. A review of studies concerning treatment adherence of patients with anxiety disorders. Patient PreferAdherence 2011;5:427-439 
Table 1. Demographic, clinical and psychological characteristics of study participants in the DAFNE Research Database.

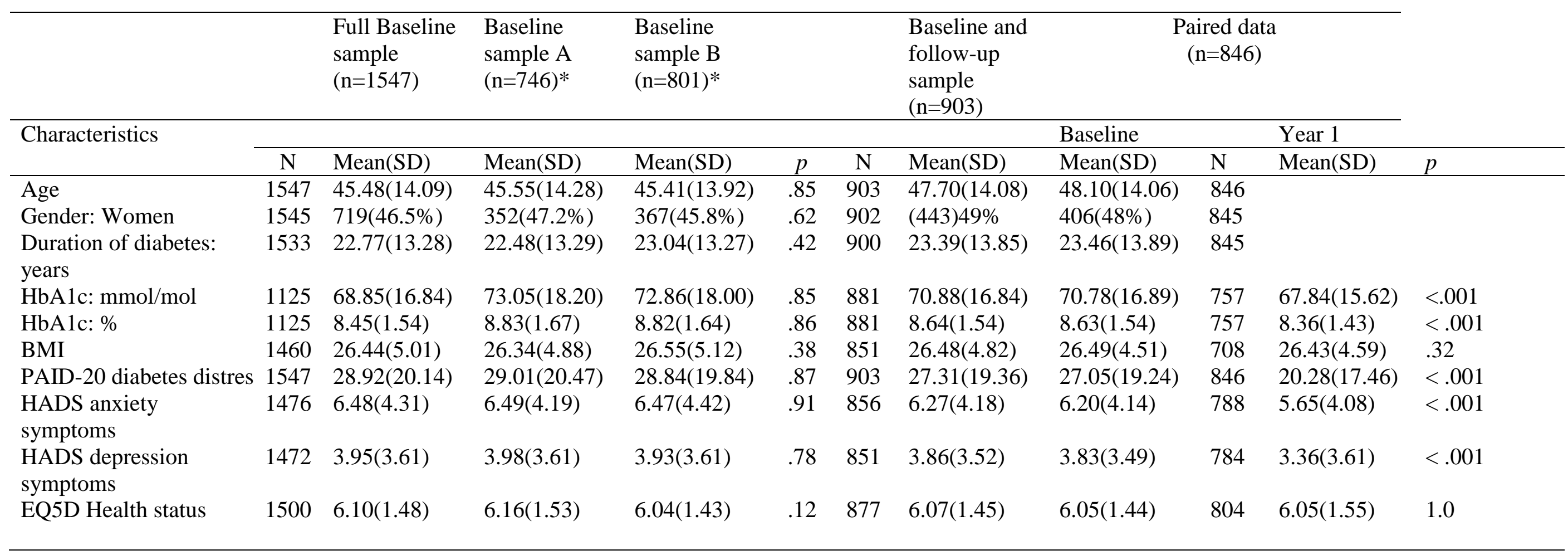

Data are Mean+/-SD or $\mathrm{n}(\%)$. P-value based on paired t-tests; independent t-tests or Chi-square tests. BMI: body mass index

* Two random samples created using random split for purposes of conducting exploratory and confirmatory factor analyses 
Table 2. Exploratory factor analysis of baseline sample A ( $n=746)$ : unforced loadings of 20-item PAID and unforced loadings and communalities of 11-item PAID when re-analysed, ranked by mean importance.

\begin{tabular}{|c|c|c|c|c|c|c|c|}
\hline \multirow[b]{2}{*}{ Item } & \multirow[b]{2}{*}{ Mean (SD) } & \multirow[b]{2}{*}{ Mode } & \multicolumn{2}{|c|}{$\begin{array}{l}\text { Initial analysis } \\
\text { of PAID-20 }\end{array}$} & \multicolumn{3}{|c|}{$\begin{array}{l}\text { Re-analysis of } \\
\text { PAID-11 }\end{array}$} \\
\hline & & & $\begin{array}{l}\text { Factor } \\
1\end{array}$ & $\begin{array}{l}\text { Factor } \\
2\end{array}$ & $\begin{array}{l}\text { Factor } \\
3\end{array}$ & $\begin{array}{l}\text { Factor } \\
1\end{array}$ & Communalities \\
\hline $\begin{array}{l}\text { Worrying about the future } \\
\text { and the possibility of serious } \\
\text { complications (PAID_12) }\end{array}$ & $2.11(1.25)$ & 2 & .741 & & & .782 & .611 \\
\hline $\begin{array}{l}\text { Feelings of guilt or anxiety } \\
\text { when you get off track with } \\
\text { your diabetes management } \\
\text { (PAID_13) }\end{array}$ & $1.76(1.23)$ & 1 & .728 & & & .745 & .555 \\
\hline $\begin{array}{l}\text { Not knowing if your mood } \\
\text { or feelings are related to } \\
\text { your diabetes (PAID_7) }\end{array}$ & $1.47(1.17)$ & 1 & .748 & & & .752 & .565 \\
\hline $\begin{array}{l}\text { Worrying about low blood } \\
\text { sugar reactions (PAID_9) }\end{array}$ & $1.47(1.17)$ & 1 & .573 & & & .591 & .350 \\
\hline $\begin{array}{l}\text { Not having clear and } \\
\text { concrete goals for your } \\
\text { diabetes care (PAID_1) }\end{array}$ & $1.38(1.15)$ & 2 & .606 & .502 & & & \\
\hline $\begin{array}{l}\text { Coping with complications } \\
\text { of diabetes (PAID_19) }\end{array}$ & $1.26(1.24)$ & 0 & .687 & & & .702 & .493 \\
\hline $\begin{array}{l}\text { Feeling discouraged with } \\
\text { your diabetes treatment plan } \\
\text { (PAID_2) }\end{array}$ & $1.23(1.13)$ & 0 & .624 & .534 & & & \\
\hline $\begin{array}{l}\text { Feeling constantly } \\
\text { concerned about food and } \\
\text { eating (PAID_11) }\end{array}$ & $1.22(1.17)$ & 0 & .738 & & & .738 & .544 \\
\hline $\begin{array}{l}\text { Feeling "burned out" by the } \\
\text { constant effort needed to } \\
\text { manage diabetes (PAID_20) }\end{array}$ & $1.19(1.20)$ & 0 & .791 & & & .796 & .634 \\
\hline $\begin{array}{l}\text { Feeling scared when you } \\
\text { think about living with } \\
\text { diabetes (PAID_3) }\end{array}$ & $1.17(1.16)$ & 0 & .774 & & & .769 & .591 \\
\hline $\begin{array}{l}\text { Feeling depressed when you } \\
\text { think about living with } \\
\text { diabetes (PAID_6) }\end{array}$ & $1.15(1.19)$ & 0 & .829 & & & .820 & .673 \\
\hline
\end{tabular}


Feeling overwhelmed by

your diabetes (PAID_8)

Feeling angry when you

$.99(1.21) \quad 0 \quad .795$

think about living with

diabetes (PAID_10)

Uncomfortable social

$.96(1.10)$

.566

situations related to your

diabetes (e.g., people telling

you what to eat) (PAID_4)

Feeling alone with your

$\begin{array}{lll}.95(1.21) \quad 0 & .766\end{array}$

.385

diabetes (PAID_17)

Feeling of deprivation

$.82(.99) \quad 0$

.635

regarding food and meals

(PAID_5)

Not ,accepting“ your

diabetes (PAID_14)

Feeling unsatisfied with

your diabetes physician

$.56(1.01)$

0

.401

.305

(PAID_15)

Feeling that your friends

$.51(.92) \quad 0 \quad .544$

.403

and family are not

supportive of your diabetes

management efforts

(PAID_18)

\begin{tabular}{lcccc}
\hline Eigenvalue & 10.17 & 1.26 & 1.06 & 6.65 \\
\hline Total scale variance & 50.84 & 6.28 & 5.30 & 60.49 \\
\hline $\begin{array}{l}\text { Internal consistency } \\
\text { reliability (Cronbach's } \\
\text { alpha) }\end{array}$ & .934 & .756 & .764 & .934 \\
\hline
\end{tabular}

Factor loadings <.30 are suppressed for clarity of presentation. The Eigenvalues in the initial analysis for the second and third factor were 1.26, and 1.06, respectively. The Eigenvalue in the re-analysis for the second factor was .68. Shaded areas represent excluded items (with reasons). An 11-item PAID was derived by excluding: one item loading <.50 (item 15), two items with high double loadings (item 1 and 2) and six items with mean score <1.0 (item 4, 5, $10,14,17$, and 18), suggesting they are least important to understanding the experience of diabetes distress. 
Table 3. Responsiveness of the PAID items for participants who completed both baseline and follow-up assessments ( $\mathrm{n}=846)$.

\begin{tabular}{|c|c|c|c|c|c|}
\hline \multirow{2}{*}{$\begin{array}{l}\text { PAID item number and } \\
\text { wording }\end{array}$} & \multicolumn{2}{|c|}{ Baseline } & \multicolumn{2}{|l|}{ Year 1} & \multirow[b]{2}{*}{ Test statistic } \\
\hline & Mean & SD & Mean & SD & \\
\hline $\begin{array}{l}\text { 1: Not having clear and } \\
\text { concrete goals for your } \\
\text { diabetes care }\end{array}$ & 1.28 & 1.11 & .73 & 1.01 & $\mathrm{t}=12.64, \mathrm{p}<.0001$ \\
\hline $\begin{array}{l}\text { 2: Feeling discouraged } \\
\text { with your diabetes } \\
\text { treatment plan }\end{array}$ & 1.15 & 1.11 & .75 & 1.03 & $\mathrm{t}=9.31, \mathrm{p}<.0001$ \\
\hline $\begin{array}{l}\text { 3: Feeling scared when } \\
\text { you think about living } \\
\text { with diabetes }\end{array}$ & 1.13 & 1.14 & .88 & 1.02 & $\mathrm{t}=6.84, \mathrm{p}<.0001$ \\
\hline $\begin{array}{l}\text { 4: Uncomfortable social } \\
\text { situation related to your } \\
\text { diabetes (e.g., people } \\
\text { telling you what to eat) }\end{array}$ & .90 & 1.02 & .62 & .87 & $\mathrm{t}=7.77, \mathrm{p}<.0001$ \\
\hline $\begin{array}{l}\text { 5: Feelings of deprivation } \\
\text { regarding food and meals }\end{array}$ & .77 & .98 & .39 & .71 & $\mathrm{t}=11.32, \mathrm{p}<.0001$ \\
\hline $\begin{array}{l}\text { 6: Feeling depressed } \\
\text { when you think about } \\
\text { living with diabetes }\end{array}$ & 1.08 & 1.17 & .88 & 1.05 & $\mathrm{t}=5.65, \mathrm{p}<.0001$ \\
\hline $\begin{array}{l}\text { 7: Not knowing if your } \\
\text { mood or feelings are } \\
\text { related to your diabetes }\end{array}$ & 1.39 & 1.20 & 1.12 & 1.13 & $\mathrm{t}=6.79, \mathrm{p}<.0001$ \\
\hline $\begin{array}{l}\text { 8: Feeling overwhelmed } \\
\text { by your diabetes }\end{array}$ & .96 & 1.10 & .72 & .97 & $\mathrm{t}=6.66, \mathrm{p}<.0001$ \\
\hline $\begin{array}{l}\text { 9: Worrying about low } \\
\text { blood sugar reactions }\end{array}$ & 1.46 & 1.16 & 1.05 & 1.06 & $\mathrm{t}=10.79, \mathrm{p}<.0001$ \\
\hline $\begin{array}{l}\text { 10: Feeling angry when } \\
\text { you think about living } \\
\text { with diabetes }\end{array}$ & .90 & 1.16 & .71 & 1.02 & $\mathrm{t}=5.61, \mathrm{p}<.0001$ \\
\hline $\begin{array}{l}\text { 11: Feeling constantly } \\
\text { concerned about food } \\
\text { and eating }\end{array}$ & 1.12 & 1.09 & .77 & .95 & $\mathrm{t}=9.66, \mathrm{p}<.0001$ \\
\hline $\begin{array}{l}\text { 12: Worrying about the } \\
\text { future and the possibility } \\
\text { of serious complications }\end{array}$ & 2.07 & 1.23 & 1.72 & 1.19 & $\mathrm{t}=8.96, \mathrm{p}<.0001$ \\
\hline
\end{tabular}




\begin{tabular}{|c|c|c|c|c|c|}
\hline $\begin{array}{l}\text { 13: Feelings of guilt or } \\
\text { anxiety when you get off } \\
\text { track with your diabetes } \\
\text { management }\end{array}$ & 1.66 & 1.16 & 1.47 & 1.18 & $\mathrm{t}=4.67, \mathrm{p}<.0001$ \\
\hline $\begin{array}{l}\text { 14: Not accepting your } \\
\text { diabetes }\end{array}$ & .70 & 1.14 & .48 & .95 & $t=6.66, p<.0001$ \\
\hline $\begin{array}{l}\text { 15: Feeling unsatisfied } \\
\text { with your diabetes } \\
\text { physician }\end{array}$ & .48 & .88 & .29 & .70 & $\mathrm{t}=6.13, \mathrm{p}<.0001$ \\
\hline $\begin{array}{l}\text { 16: Feeling that diabetes } \\
\text { is taking up too much of } \\
\text { your mental and physical } \\
\text { energy every day }\end{array}$ & 1.06 & 1.09 & .89 & 1.03 & $\mathrm{t}=4.75, \mathrm{p}<.0001$ \\
\hline $\begin{array}{l}\text { 17: Feeling alone with } \\
\text { your diabetes }\end{array}$ & .86 & 1.12 & .63 & .96 & $\mathrm{t}=6.22, \mathrm{p}<.0001$ \\
\hline $\begin{array}{l}\text { 18: Feeling that your } \\
\text { friends and family are } \\
\text { not supportive of your } \\
\text { diabetes management } \\
\text { efforts }\end{array}$ & .44 & .82 & .37 & .75 & $\mathrm{t}=2.48, \mathrm{p}=.013^{*}$ \\
\hline $\begin{array}{l}\text { 19: Coping with } \\
\text { complications of diabetes }\end{array}$ & 1.17 & 1.20 & .93 & 1.12 & $\mathrm{t}=6.03, \mathrm{p}<.0001$ \\
\hline $\begin{array}{l}\text { 20: Feeling "burned out" } \\
\text { by the constant effort } \\
\text { needed to manage } \\
\text { diabetes }\end{array}$ & 1.07 & 1.15 & .85 & 1.08 & $\mathrm{t}=5.95, \mathrm{p}<.0001$ \\
\hline
\end{tabular}

* Difference between baseline and one-year follow-up for item 18 exceeds the Bonferroni correction for multiple comparisons $(\mathrm{p}<.003)$ and is not considered significant. 


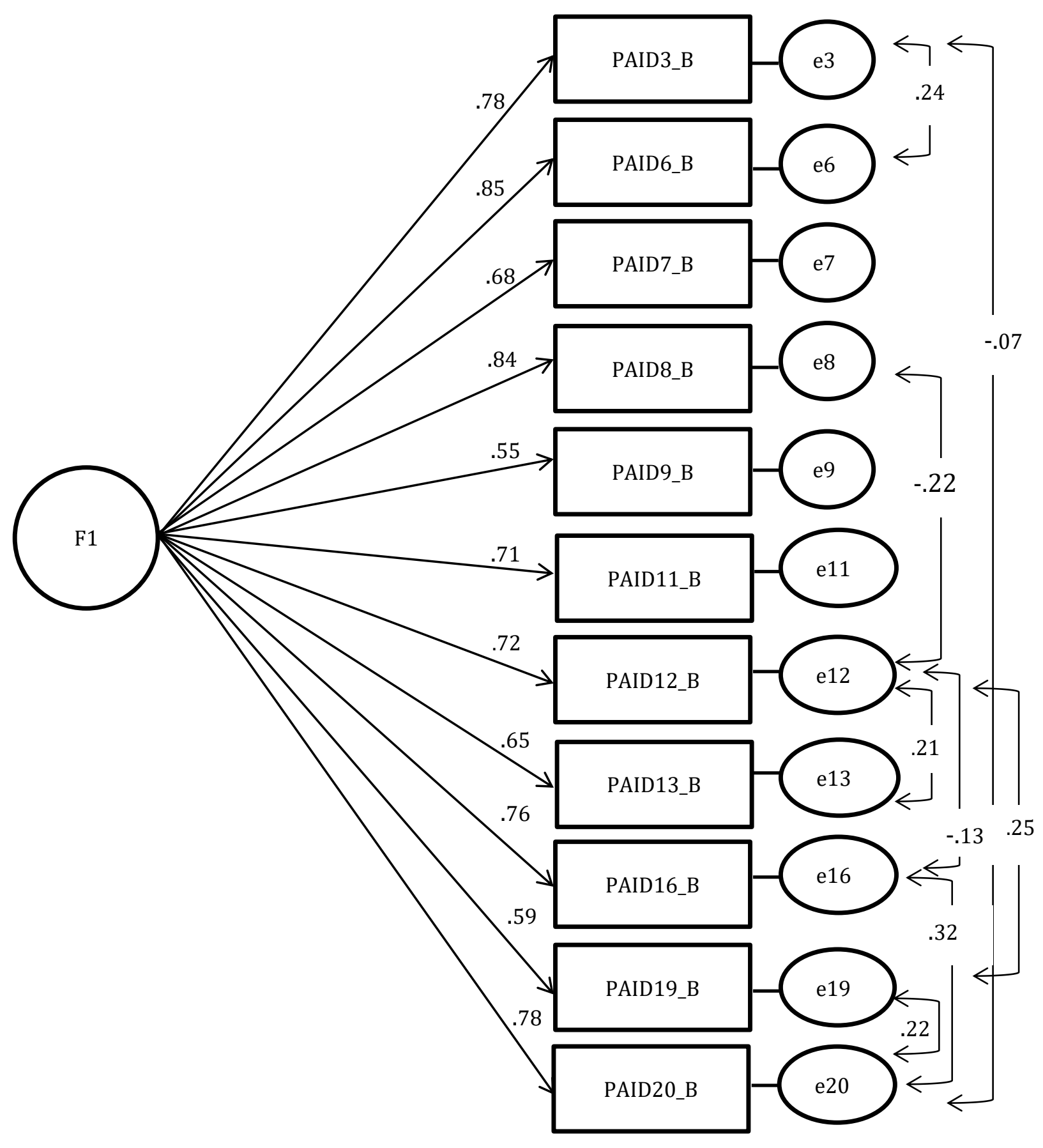

Fig. 1a. Confirmatory factor analysis of PAID-11 using baseline sample B ( $\mathrm{n}=801)$. 


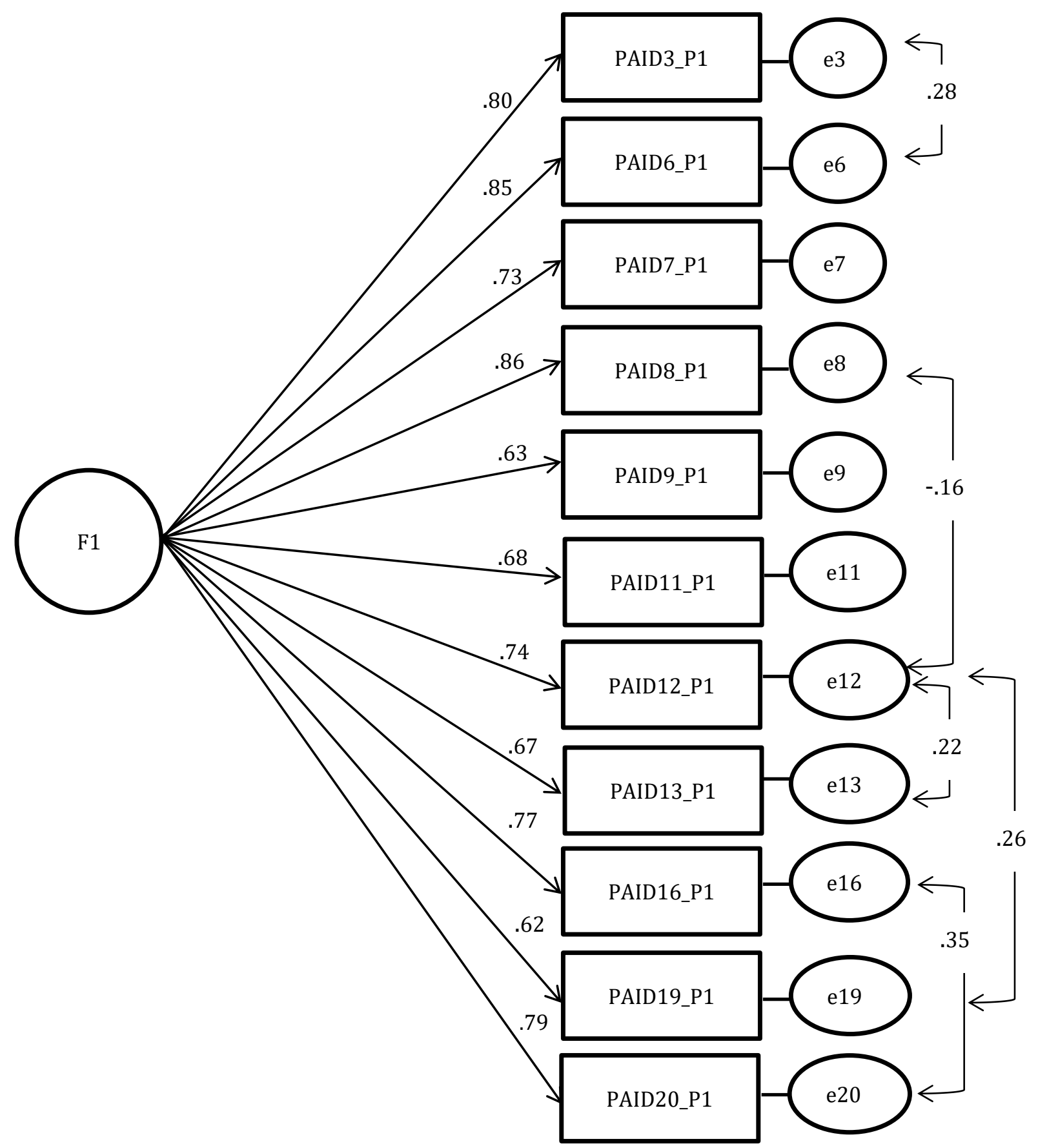

Fig. 1b. Confirmatory factor analysis of PAID-11 using one-year follow up data ( $\mathrm{n}=846$ ). 
Appendix A: PAID-11 measure

INSTRUCTIONS: Which of the following diabetes issues are currently a problem for you? Circle the number that gives the best answer for you. Please provide an answer for each question.

\begin{tabular}{|l|c|c|c|c|c|}
\hline & $\begin{array}{c}\text { Not a } \\
\text { problem }\end{array}$ & $\begin{array}{c}\text { Minor } \\
\text { problem }\end{array}$ & $\begin{array}{c}\text { Moderate } \\
\text { problem }\end{array}$ & $\begin{array}{c}\text { Somewhat } \\
\text { serious } \\
\text { problem }\end{array}$ & $\begin{array}{c}\text { Serious } \\
\text { problem }\end{array}$ \\
\hline $\begin{array}{l}\text { Feeling scared when you think } \\
\text { about living with diabetes? }\end{array}$ & 0 & 1 & 2 & 3 & 4 \\
\hline $\begin{array}{l}\text { Feeling depressed when you } \\
\text { think about living with diabetes? }\end{array}$ & 0 & 1 & 2 & 3 & 4 \\
\hline $\begin{array}{l}\text { Not knowing if your mood or } \\
\text { feelings are related to your } \\
\text { diabetes? }\end{array}$ & 0 & 1 & 2 & 3 & 4 \\
\hline $\begin{array}{l}\text { Feeling overwhelmed by your } \\
\text { diabetes? }\end{array}$ & 0 & 1 & 2 & 3 & 4 \\
\hline $\begin{array}{l}\text { Worrying about low blood sugar } \\
\text { reactions? }\end{array}$ & 0 & 1 & 2 & 3 & 4 \\
\hline $\begin{array}{l}\text { Feeling constantly concerned } \\
\text { about food and eating? }\end{array}$ & 0 & 1 & 2 & 3 & 4 \\
\hline $\begin{array}{l}\text { Worrying about the future and the } \\
\text { possibility of serious } \\
\text { complications? }\end{array}$ & 0 & 1 & 2 & 3 & 4 \\
\hline $\begin{array}{l}\text { Feelings of guilt or anxiety when } \\
\text { you get off track with your } \\
\text { diabetes management? }\end{array}$ & 0 & 1 & 2 & 3 & 4 \\
\hline $\begin{array}{l}\text { Feeling that diabetes is taking up } \\
\text { too much of your mental and } \\
\text { physical energy every day? }\end{array}$ & 0 & 1 & 2 & 3 & 4 \\
\hline $\begin{array}{l}\text { Coping with complications of } \\
\text { diabetes? }\end{array}$ & 0 & 1 & 2 & 3 & 4 \\
\hline $\begin{array}{l}\text { Feeling "burned out" by the } \\
\text { constant effort needed to manage } \\
\text { diabetes? }\end{array}$ & 0 & 0 & 3 & 4 \\
\hline Items are presented in the ord of & 0 & & 3 & 4 \\
\hline
\end{tabular}

Items are presented in the order of the original PAID-20 scale. To obtain a total score, sum all the scores together (items 3, 6, 7, 8, 9, 11, 12, 13, 16, 19, and 20 from original PAID-20). The total score ranges from 0 to 44 , with higher scores indicating greater diabetes distress. Scores $\geq 18$ indicate severe diabetes distress. 